\title{
Os padrões de metadados como recursos tecnológicos para a garantia da preservação digital
}

\author{
Danilo Formenton \\ Fabiano Ferreira de Castro \\ Luciana de Souza Gracioso \\ Ariadne Chloe Mary Furnival \\ Universidade Federal de São Carlos - UFSCar, Brasil
}

Maria da Graça de Melo Simões

Universidade de Coimbra - UC, Portugal

REVIEW

\begin{abstract}
Resumo
A garantia de preservação digital a longo prazo só será possível com a adoção efetiva de padrões ou esquemas de metadados, pois são eles que determinarão a descrição, a representação, a consistência e a persistência do recurso/objeto digital no ambiente informacional, além de definir a interoperabilidade entre sistemas. A adoção de metadados para preservação apoia a administração dos processos relativos ao arquivamento e à manutenção do acesso à informação digital a longo prazo, com garantias de autenticidade, de integridade e de confiabilidade. Neste cenário, foi objetivo do trabalho identificar e descrever padrões ou esquemas de metadados que poderiam ser considerados por instituições que estão desenvolvendo seus repositórios institucionais, para que possam contemplar a preservação digital. Para tanto, foi desenvolvida pesquisa bibliográfica e sistematização e análise de conteúdo. Foram selecionados e analisados os seguintes esquemas e padrões de metadados: DUBLIN CORE, MODS, EAD, ANSI/NISO Z39.87, METS e o PREMIS. A análise dos resultados indica que os metadados descritivos e técnicos do DC, MODS, EAD e ANSI/NISO Z39.87 ou MIX, possuem um papel mais direcionado a amparar o METS e o PREMIS, tanto na descoberta e no registro dos aspectos técnicos do objeto digital, como na comprovação de sua procedência, autenticidade, contexto e integridade. Englobando metadados descritivos, estruturais, administrativos e de preservação do PREMIS, o METS pode gerir os objetos digitais atuando como um Pacote de Submissão de Informação (PSI), Pacote de Arquivamento de Informação (PAI) ou Pacote de Disseminação de Informação (PDI) num Sistema Aberto de Arquivamento de Informação (SAAI).
\end{abstract}

Palavras-chave

Ciência da Informação; Informação e tecnologia; Metadados de preservação; Padrões de metadados; Preservação digital

\section{Metadata standards as a technological resource to guarantee digital preservation}

\begin{abstract}
The guarantee of long-term digital preservation will only be possible with the effective implementation of metadata standards or schemas, because these will determine the description, representation, consistency and persistence of the digital resource/object in information environments, as well as defining interoperability between systems. The adoption of metadata for preservation supports the management of processes for the archiving and maintenance of access to digital information in the long term, guaranteeing authenticity, integrity and reliability. In this scenario, the aim of this study was to identify and describe metadata standards or schemas that could be considered by institutions that are developing their institutional repositories, so that digital preservation might be addressed. To that end, a literature review, and its systematization and content analysis were carried out. The following metadata standards and schemas were selected and analyzed: DUBLIN CORE (DC), MODS, EAD, ANSI/NISO Z39.87, METS and PREMIS. The results indicate that the descriptive and technical metadata DC, MODS, EAD and ANSI/NISO Z39.87 or MIX have a role that is more directed to supporting METS and PREMIS, both in discovering and recording the technical aspects of digital objects, and in the proof of its provenance, authenticity, context and integrity. Encompassing descriptive, structural, administrative and preservation metadata of PREMIS, METS can manage digital objects acting as a Submission Information Package (SIP), Archival Information Package (AIP) or Dissemination Information Package (DIP) in an Open Archival Information System (OAIS).
\end{abstract}




\section{Introdução}

Para a efetivação e sucesso pleno do acesso à informação, é requisito primordial que se encontre esta preservada, seja em suporte tradicional seja em suporte digital. As sociedades contemporâneas são grandes produtoras e consumidoras de informação. O uso generalizado das Tecnologias da Informação e Comunicação (TIC) motivou profundas alterações na forma como a informação passou a ser produzida, difundida, armazenada e preservada. $\mathrm{O}$ impacto das tecnologias atuais nas sociedades modernas é de tal ordem que está na origem de um tipo de sociedade em que a informação adquiriu um novo valor social, cultural e económico - a Sociedade da Informação.

No contexto atual, a informação é entendida como um bem precioso, imprescindível para o desenvolvimento da sociedade, pois ela é a alavanca do progresso e da riqueza. Deste modo, as TIC, associadas à World Wide Web, tornaram-se ferramentas insubstituíveis no que diz respeito à produção, à disseminação e ao consumo da informação, motivando consequentemente um aumento exponencial da sua produção e publicação. Apesar da relevância dos meios analógicos, a maior parte da informação, nas sociedades contemporâneas, passou a ser produzida digitalmente, seja nas esferas públicas ou privadas; sendo que a gestão e a organização dessa informação têm afetado não só as tradicionais instituições de memória (arquivos, bibliotecas, centros de documentação, museus etc.), como também instituições como bancos, hospitais, e empresas privadas de todo o gênero.

As vantagens e os atrativos dos documentos digitais comparadas às dos documentos analógicos, são evidentes. Entre elas salienta-se o fato de poderem agregar conteúdos multimídia e ocuparem pouco volume quando comparados com os equivalentes analógicos; a volatilização do suporte deslocaliza-os no tempo e no espaço, permitindo o acesso simultâneo de várias pessoas ao mesmo documento. Além disso, são facilmente transmissíveis, replicáveis e editáveis. O fato de apresentarem estas especificidades, a preservação dos documentos digitais coloca novos desafios: o acesso aos documentos depende do ambiente tecnológico que permite reproduzi-los; a sua virtualidade e volatilidade obrigam a repensar aspectos como a autenticidade e a integridade, os direitos de autor, a autoria, o controlo de versões, assim como estudar procedimentos técnicos e computacionais (softwares e hardwares), formatos, modelos, metadados e padrões de metadados para que a sua preservação seja eficaz e deste modo, não crie entropias no momento da recuperação.

O novo contexto obriga as instituições de memória (em particular, as bibliotecas) a repensarem a forma como preservam as suas coleções (as que se encontram em formato analógico e as de formato digital) para poderem continuar ser curadoras do património literário, científico e cultural. Por essa razão, não é de estranhar que estas tenham sido as primeiras instituições de memória (década de 80) a alertar para a necessidade de definir medidas e estratégias que permitissem preservar a informação digital a longo prazo. A partir dos anos de 1990 do século passado, começou a assistir-se a movimentações nesse sentido, tornando-se necessário, definir conceitos, identificar problemas e ameaças e delinear estratégias de atuação no âmbito da preservação digital. Foi no mundo anglo-saxônico, pioneiro nesta área de estudo, que surgiram os primeiros estudos e publicações sobre preservação digital. Paralelamente às bibliotecas dos Estados Unidos da América e da Grã-Bretanha, as bibliotecas da Europa e da Oceania, sobretudo as universitárias, começam a implementar os primeiros projetos de preservação digital, cientes do que este seria o meio para a preservação da sua memória coletiva, isto é, da sua história.

Com o advento e a expansão do acesso à Internet em consonância com o uso intensivo das TIC, no desenvolvimento de ambientes informacionais tornou-se notório o expressivo aumento gradativo na produção de recursos informacionais, principalmente em formato digital. Garantir a autenticidade, a integridade e a preservação dos recursos digitais, é apontado pela comunidade científica, principalmente pela Ciência da Informação, como um dos grandes desafios do século XXI.

Uma das estratégias de preservação digital existentes refere-se à adoção de padrões de metadados, estruturas formais de descrição de recursos para comunidades específicas, de modo a apoiar a gestão e a preservação de objetos digitais em ambientes informacionais, tais como os repositórios institucionais.

Considerando a hipótese de que há uma carência de estudos nacionais de preservação digital na Ciência da Informação e áreas afins que sistematizam e analisam em profundidade os metadados e as características de 
esquemas de metadados aplicáveis à preservação digital, é que se reconheceu a necessidade de identificar e descrever quais padrões ou esquemas de metadados poderiam ser considerados pelas instituições que estão desenvolvendo seus repositórios institucionais, para que estas pudessem contemplar a preservação digital. Objetiva-se ainda, mais especificamente verificar em que medida os padrões ou esquemas de metadados no âmbito da preservação digital têm sido discutidos pela Ciência da Informação e áreas afins (Arquivologia, Biblioteconomia, Museologia etc.), apontando elementos de metadados que poderiam atender as demandas de estruturação de repositórios institucionais de maneira mais adequada para a preservação de documentos digitais.

Trata-se de uma pesquisa exploratória que utiliza como método de coleta de dados, a pesquisa bibliográfica, a partir de uma revisão de literatura direcionada e concernente aos padrões ou esquemas de metadados utilizados no escopo da preservação digital. A partir da análise do conteúdo da revisão da literatura especializada, foram reconhecidas e sistematizadas algumas definições e classes para metadados; o conceito de metadados de preservação e as informações requeridas para a preservação de longo prazo; além dos principais padrões de metadados utilizados no suporte ao gerenciamento da preservação digital. O presente trabalho se propõe então a apresentar os resultados e as análises destes conteúdos.

O resultado deste mapeamento e análise vislumbrou contribuir para possíveis delimitações do conjunto de diretrizes e políticas a serem adotadas pelas instituições interessadas e/ou envolvidas com a preservação e o acesso ao longo do tempo de informações digitais.

\section{Definições e classificações de metadados}

A concepção de metadados está fundamentada na tradicional atividade de catalogação em bibliotecas, cuja principal função é descrever um recurso informacional de forma única, multidimensionando suas formas de acesso, garantindo sua recuperação pelo usuário final, num ambiente/sistema informacional (convencional ou digital).

O ambiente digital pode ser retratado, segundo Campos (2002) e Saramago (2002), como aquele que se caracteriza pela fragilidade, volatilidade e permanente dinâmica. Por sua vez, os objetos digitais a serem mantidos, sejam eles nascidos digitais ou digitalizados, são também dinâmicos e vulneráveis quanto a sua alta dependência de tecnologias que se tornam obsoletas rapidamente ou que são danificadas fisicamente (FORMENTON; GRACIOSO; CASTRO, 2015).

Há na literatura científica da área de Ciência da Informação várias definições e conceitos sobre metadados e padrões de metadados. Neste trabalho nos deteremos ao conceito de metadados determinado por Grácio (2012, p.121), pois este contempla as principais características e as metodologias para garantir a preservação digital; os metadados referem-se à "[...] um conjunto de dados, chamados 'elementos', cujo número varia de acordo com o padrão adotado, e que descreve o recurso, possibilitando a um usuário ou a um mecanismo de busca acessar e recuperar esse recurso".

Através de Barbedo, Corujo e Sant'Ana (2011) são observadas múltiplas categorias funcionais de tipos de metadados, que são assim entendidas:

- Metadados descritivos ou de identificação - visam à pesquisa, recuperação e identificação. Podem conter elementos como, por exemplo, título, autor, assunto e palavras-chave.

- Metadados estruturais - vinculam de forma hierárquica distintos objetos digitais (textos, imagens, áudios etc.) integrantes de um mesmo documento ou recurso informacional.

- Metadados administrativos - dispõem informações que suportam a gerência dos recursos arquivísticos eletrônicos. Incluem de que forma e em que ocasião os recursos foram gerados, espécie de ficheiro ou de arquivo de computador e demais informações técnicas, além dos titulares com direitos ou permissões de acesso. 
- Metadados técnicos - especificam os aspectos técnicos dos arquivos e dos seus formatos.

- Metadados de preservação - incluem informações requeridas ao arquivamento e salvaguarda dos objetos digitais ao longo do tempo.

Para os propósitos da presente investigação destacaremos a categoria de metadados relativos à preservação de longo prazo, uma vez que são fundamentais para a consecução de uma efetiva gerência e preservação dos recursos/objetos digitais.

\section{Metadados para a preservação digital}

Os metadados de preservação são essenciais para a preservação digital. De acordo com Sayão (2010, p.10) estes tipos de metadados são conceituados "[...] de uma forma simples e direta, como a informação que apoia e documenta a preservação de longo prazo de materiais digitais". Em Saramago (2004, p.1) compreende-se por metadados de preservação "[...] como informação de apoio aos processos associados com a preservação digital de longo prazo". Para Arellano (2008) tratam-se daqueles associados ao conteúdo do recurso, seu contexto e estrutura de criação/produção, além das alterações ocorridas em todo o seu ciclo de vida.

Reunindo as ponderações de Barbedo, Corujo e Sant'Ana (2011), Campos e Saramago (2007), National Museum of Australia (2012), Saramago (2004), Sayão (2010) e Grácio (2012), pode-se identificar algumas das distintas informações e funções inter-relacionadas circunscritas pela obtenção, geração, guarda e manutenção de metadados para preservação, tais como:

- Registro do histórico, do hardware, software e outras dependências técnicas, das estruturas e das mudanças (de custódia legal e física ou de natureza tecnológica, social etc.) suportadas pelos recursos/objetos digitais, no decurso de todo o seu ciclo de vida (isto é, criação, seleção e descarte, identificação persistente, descrição e acesso, armazenamento e preservação).

- Documentação das tomadas de decisão e atos de preservação, dos métodos de preservação e seus resultados, das ações de gestão de coleções e direitos, além dos próprios metadados, de modo a apoiar os processos ou as iniciativas correntes e vindouras de preservação digital.

- Suporte à descoberta, localização, recuperação, referência única e persistente, preservação, acesso, utilização, comprovação de autenticidade e integridade, bem como gestão de direitos de propriedade intelectual de objetos arquivísticos e museológicos digitais ou eletrônicos.

- Assistência à uma ideal gerência dos objetos digitais, dos sistemas de informação (registros de correspondência e de documentos, registros de funcionamento dos sistemas e seus acessos por intermédio de práticas de auditorias mantidas pelos serviços de TIC, por exemplo), da comunidade usuária e das funcionalidades a serem oferecidas.

Em suma, os metadados de preservação registram informações do conteúdo de recursos digitais e dados administrativos, estruturais e técnicos para preservação digital. Esses metadados propiciam a preservação por longo prazo e o acesso contínuo aos objetos digitais, com garantias de autenticidade, de integridade e de confiabilidade. Neste cenário, a determinação e, possivelmente, adaptação de padrões de metadados torna-se uma ação indispensável e complexa, devendo-se incorporar os vários tipos específicos de processos e de recursos digitais tratados e preservados, o rol abundante de informações a serem registradas e fornecidas e, ainda, as decisões tomadas diante de um futuro de imprevisões intrínsecas à preservação em ambientes digitais.

\section{Identificação dos esquemas e padrões de metadados para preservação digital}

A organização dos metadados dá-se em estruturas formais chamadas de esquemas de metadados, que consistem de conjuntos de elementos concebidos para um fim específico, como a descrição de um certo tipo de recurso de informação. Na literatura, as expressões "esquema", "formato", "sistema" e "conjuntos de elementos" têm sido usadas indistintamente para se referir a padrões de metadados (CHAN; ZENG, 2006; NATIONAL 
INFORMATION STANDARDS ORGANIZATION, 2004). De acordo com Zeng e Qin (2008, p.323, tradução nossa) o esquema de metadados (Metadata schema) pode ser considerado como:

\footnotetext{
Uma especificação processavelmente por máquinas que define a estrutura, a codificação de sintaxe, regras, e formatos para um conjunto de elementos de metadados em uma linguagem formal num esquema. Na literatura 0 termo "metadata schema" usualmente refere-se ao conjunto de elementos na sua totalidade, assim como a codificação dos elementos e a estrutura com uma linguagem de marcação.
}

De fato, o "esquema" é uma entidade total contendo os componentes semânticos e de conteúdo (tidos como um "conjunto de elementos"), bem como a codificação dos elementos com uma sintaxe ou linguagem de marcação, como Standard Generalized Markup Language (SGML) e Extensible Markup Language (XML). Assim, um conjunto de elementos de metadados dispõe de dois componentes básicos: 1) Semântica - as definições ou os significados dos elementos e seus refinamentos; e 2) Conteúdo - as declarações ou as instruções de quais e como os valores devem ser atribuídos para os elementos. Para cada elemento definido, um padrão de metadados geralmente especifica regras de conteúdo para como o conteúdo deve ser criado ou incluído (por exemplo, como identificar o título principal), regras de representação para conteúdo (por exemplo, padrões de representação do tempo) e valores de conteúdo admissíveis (isto é, se os termos devem ser tomados a partir de um vocabulário controlado específico ou podem ser providos pelo autor, derivados do texto, ou aditados pelo trabalho de criadores de metadados sem uma lista de termos controlados). Pode haver ainda regras de sintaxe para codificação dos elementos e seu conteúdo (CHAN; ZENG, 2006; NATIONAL INFORMATION STANDARDS ORGANIZATION, 2004).

Da revisão e da análise da literatura pode-se identificar variados padrões ou esquemas de metadados usados para a descrição de recursos em distintos domínios. Múltiplos padrões de metadados vêm sendo elaborados para uma extensa diversidade de usos e âmbitos específicos, todavia, os esquemas são delimitados por seus próprios conjuntos de elementos de metadados, particularidades e domínios de utilização. A seguir são discutidos alguns dos principais e mais correntes padrões apontados pela literatura especializada para a preservação digital. Contudo, não serão descritos todos os elementos de cada padrão e sim será feita a menção somente aos elementos que fazem parte da análise dos resultados, momento em que são apresentados o mapeamento e a indicação de elementos para a preservação digital. O estudo sistematizado dos padrões elencados poderá ser consultado na íntegra em Formenton (2015), assim com outras informações complementares relacionadas ao assunto deste trabalho.

\subsection{Padrão Dublin Core}

O padrão Dublin Core (DC) tem sua origem em Chicago, na $2^{-a}$ Conferência Internacional World Wide Web, em 1994, numa discussão sobre semântica e a Web enfocada na dificuldade da descoberta de recursos de informação. Posteriormente, a Online Computer Library Center (OCLC) e o National Center for Supercomputing Applications (NCSA) organizaram um evento em Dublin, Ohio, em 1995. No evento, intitulado de "OCLC/NCSA Metadata Workshop", mais de 50 profissionais debateram como um conjunto semântico seria útil para a busca e a recuperação de recursos baseados na Web. Como resultado definiu-se um conjunto básico de elementos de metadados chamado "Dublin Core", em razão do local do evento (DUBLIN CORE METADATA INITIATIVE, c2015; HARPER, 2010).

Existem dois níveis no padrão DC: Simples e Qualificado. Sendo assim, o DC Simples inclui quinze elementos; e o DC Qualificado compreende três elementos adicionais (Audiência, Proveniência e Detentor de Direitos), assim como um grupo de refinamentos ou qualificadores de elementos, que aperfeiçoam a semântica dos elementos de maneira que possam ser úteis na descoberta de recursos. O DC apresenta algumas características, que refletem também os seus objetivos, dentre os quais são as seguintes: simplicidade, interoperabilidade semântica, consenso internacional, extensibilidade e flexibilidade. (GRÁCIO, 2012; HILLMANN, 2005).

O DC está entre os padrões mais usados por comunidades internacionais para descoberta de recursos no domínio Web. É representado por meio de diversas sintaxes como, por exemplo, codificado em HyperText Markup Language (HTML), ou em Resource Description Framework (RDF) usando XML. Embora o DC tenha uma capacidade descritiva para prestar o acesso e seja um expoente de interoperabilidade na Web, este esquema é muito simples e menos eficaz quanto à preservação digital e à efetuação do papel dos metadados administrativos e estruturais de documentar, por exemplo, o histórico de estratégias de preservação adotadas no recurso digital e os componentes de hardware e software (CAMPOS; SARAMAGO, 2007; HILLMANN, 2005). 


\subsection{Padrão MODS}

Criado pela Library of Congress (LC) e disponível em 2002, o esquema de metadados bibliográficos Metadata Object Description Schema (MODS) pode ser aplicado para objetos de bibliotecas digitais. Expresso em XML, o MODS contém um subconjunto de campos MARC 21 e utiliza elementos textuais, ao invés de códigos numéricos, possibilitando uma fácil compreensão.

Atualmente na versão 3.6, o padrão MODS apresenta um conjunto de vinte elementos de metadados descritivos principais (LIBRARY OF CONGRESS, 2014).

O esquema MODS fornece informações bibliográficas importantes que apoiam outros padrões expressos em XML, como o Metadata Encoding and Transmission Standard (METS) e o PREservation Metadata: Implementation Strategies (PREMIS). Sob o enfoque da preservação digital, três elementos MODS merecem atenção: Informação de Origem, Item Relacionado e Condição de Acesso. Estes elementos registram informações que são úteis para auxiliar os metadados de preservação na corroboração da proveniência, autenticidade e integridade dos objetos digitais, bem como no reconhecimento dos direitos associados ao recurso que podem intervir, sobretudo, na realização das ações de preservação, de acesso e de utilização dos seus respectivos conteúdos.

\subsection{Padrão EAD}

O padrão Encoded Archival Description (EAD) tem seu início num projeto da biblioteca da Universidade da Califórnia, Berkeley, em 1993. Este projeto investigou a oportunidade e a viabilidade de desenvolver um padrão de codificação não-proprietário para instrumentos de pesquisa legíveis por computador, tais como índices, registros, inventários, ou guias elaborados por arquivos, bibliotecas, museus e repositórios de manuscritos, que proporcionam informações acerca de determinadas coleções de materiais arquivísticos.

Conforme Andrade (2007), Barbedo et al. (2007), Gama e Ferneda (2010) e Society of American Archivists (2002), na versão de 2002 um documento EAD contém três partes.

Na preservação digital o uso do EAD é cabível pois, para Barbedo, Corujo e Sant'Ana (2011), trata-se de um esquema completo e que atende as normas de descrição arquivística. Os padrões de metadados descritivos, tal como o DC, o MODS e o próprio EAD, apesar de serem mais propícios à descoberta e recuperação de recursos ao invés da preservação de longo prazo, são esquemas importantes para o registro de algumas informações de apoio aos metadados de preservação, no tocante à proveniência, autenticidade, integridade, contexto técnico, direitos, e à custódia/propriedade dos recursos armazenados num repositório de preservação digital.

\subsection{Padrão ANSI/NISO Z39.87}

O padrão American National Standards Institute (ANSI)/National Information Standards Organization (NISO) Z39.87 tem sua origem no "Image Metadata Workshop", evento patrocinado pela NISO, Council on Library and Information Resources (CLIR) e Research Libraries Group (RLG), em abril de 1999, que se propôs a promover um trabalho cooperativo para determinar um conjunto de elementos de metadados para documentar atributos técnicos de imagens fixas digitais. Na norma ANSI/NISO Z39.87-2006 (R2011) os elementos visam ser harmônicos com os metadados de preservação do PREMIS, sendo que um esquema em XML, aludido como NISO Metadata for Images in XML (MIX), está em construção para intercambiar e/ou armazenar os elementos de metadados técnicos especificados na ANSI/NISO Z39.87-2006 (NATIONAL INFORMATION STANDARDS ORGANIZATION, c2011).

Através de National Information Standards Organization (c2011), a versão atual de 2011 agrupa os elementos do padrão ANSI/NISO Z39.87 em cinco principais seções.

O ANSI/NISO Z39.87 não tem como escopo metadados para o registro da proveniência, autenticidade, integridade, ou dos direitos e propriedade intelectual de imagens. Na preservação digital o uso do padrão pode ser contextualizado através de dois projetos notáveis: em Portugal, o Repositório de Objectos Digitais Autênticos (RODA) da Direção-Geral do Livro, dos Arquivos e das Bibliotecas (DGLAB) e da Universidade do Minho; e nos Estados Unidos, University of Houston Digital Library (UHDL). Para a guarda de metadados de preservação, estruturais e descritivos o RODA utiliza, nessa ordem, o PREMIS, o METS e o EAD, tendo o Z39.87 de apoio ao PREMIS na guarda de metadados técnicos de imagens. Por outro lado, a UHDL preserva registros METS 
gerados por softwares (JHOVE e 7train) através de metadados descritivos DC e de metadados técnicos MIX (BARBEDO et al., 2007; CHEN; REILLY, 2011; NATIONAL INFORMATION STANDARDS ORGANIZATION, c2011).

\subsection{Padrão METS}

O METS teve como antecedente o projeto Making of America II (MOA2), que forneceu um esquema de codificação para metadados para obras textuais e baseadas em imagens. Usando a linguagem XML, o METS concede um padrão para codificação de metadados - descritivos, administrativos e estruturais - tanto para a administração de objetos de bibliotecas digitais num repositório como também para o intercâmbio destes objetos digitais entre repositórios (ou entre repositórios e seus usuários).

Segundo Barbedo et al. (2007), Campos e Saramago (2007), Grácio (2012), Library of Congress (2011) e Sayão (2010) um documento METS compõe sete principais seções.

O METS é relevante na preservação digital, pois está escrito em XML, entretanto, a flexibilidade na implementação do METS pode inibir o intercâmbio de registros causando assim problemas de interoperabilidade entre sistemas; e na utilização do METS com o PREMIS pode ocorrer duplicações ou, ainda, uma parcial harmonia entre seus elementos (LAVOIE; GARTNER, 2013; RODRIGUES, 2008; SAYÃO, 2010).

\subsection{Padrão PREMIS}

O PREMIS denota o nome de um grupo de trabalho internacional patrocinado pela RLG e OCLC, no período de 2003 a 2005. Tal grupo de trabalho produziu um relatório final chamado "PREMIS Data Dictionary for Preservation Metadata", que define um conjunto de metadados básicos, implementáveis e de ampla aplicação, para apoiar a preservação digital em sistemas de repositórios. O Dicionário de Dados PREMIS, atualmente na versão 3.0, propicia orientações para o preenchimento e o gerenciamento dos metadados de preservação.

Com base em Barbedo et al. (2007), Campos e Saramago (2007), Caplan (2009) e Sayão (2010), o Dicionário de Dados PREMIS organiza-se de acordo com um modelo de dados que correlaciona cinco tipos de entidades compreendidas nos processos de preservação digital.

Promovido pela LC, o PREMIS Maintenance Activity oferece um esquema XML que corresponde diretamente ao Dicionário de Dados, permitindo a descrição de objetos, eventos, agentes e direitos, assim como a utilização do PREMIS representado em XML para a gerência e o intercâmbio de metadados entre sistemas de preservação.

\section{Análise dos padrões de metadados à luz da preservação digital}

Os padrões DC, MODS, EAD, ANSI/NISO Z39.87, METS e PREMIS tem um conjunto de características em comum e algumas particularidades. As ponderações feitas respaldaram-se nos requisitos para a preservação digital, no modelo de informação SAAI e nas informações registradas e expressas pelos metadados de preservação. O Quadro 1 sintetiza o escopo, os aspectos elementares dos padrões e os elementos de metadados julgados nesta investigação como importantes para a preservação digital. 
Quadro 1 - Padrões e elementos de metadados de apoio à preservação digital (Continua).

\begin{tabular}{|c|c|c|c|c|}
\hline Padrão & Características & \multicolumn{2}{|c|}{$\begin{array}{c}\text { Elementos de metadados úteis para a } \\
\text { preservação digital }\end{array}$} & Escopo \\
\hline $\begin{array}{c}\text { DC } \\
\text { Qualificado }\end{array}$ & $\begin{array}{l}\text { - Esquema flexível e } \\
\text { extensível de } \\
\text { metadados descritivos } \\
\text { para descoberta de } \\
\text { recursos Web. } \\
\text { - Mantido pela DCMI } \\
\text { vêm sendo muito } \\
\text { usado por } \\
\text { comunidades } \\
\text { internacionais. } \\
\text { - Pode ser } \\
\text { representado em XML } \\
\text { e propicia } \\
\text { interoperabilidade de } \\
\text { dados na Web. }\end{array}$ & $\begin{array}{ll}\text { - } & \text { Título } \\
\text { - } & \text { Criador } \\
\text { - } & \text { Descrição } \\
\text { - } & \text { Data } \\
\text { - } & \text { Formato } \\
\text { - Identificador } \\
\text { - Fonte }\end{array}$ & $\begin{array}{ll}\text { - } & \text { Relação } \\
\text { - } & \text { Cobertura } \\
\text { Direitos } \\
\text { Detentor de } \\
\text { Direitos } \\
\text { Proveniência }\end{array}$ & $\begin{array}{l}\text { Padrão para suporte a } \\
\text { descoberta de recursos } \\
\text { eletrônicos na Web } \\
\text { (CAMPOS; SARAMAGO, } \\
\text { 2007; GRÁCIO, 2012; } \\
\text { SAYÃO, 2010). }\end{array}$ \\
\hline MODS & $\begin{array}{l}\text { - Esquema XML } \\
\text { aplicável aos objetos } \\
\text { de bibliotecas digitais e } \\
\text { mantido pela LC. } \\
\text { - Elementos descritivos } \\
\text { herdam a semântica } \\
\text { dos elementos MARC } \\
21 . \\
\text { - É mais simples que } \\
\text { MARC completo e mais } \\
\text { rico que o DC } \\
\text { Qualificado. }\end{array}$ & $\begin{array}{l}\text { Informação de } \\
\text { Título } \\
\text { - } \\
\text { - Inome } \\
\text { Origem } \\
\text { Descrição Física } \\
\text { Índice } \\
\text { - Item Relacionado de }\end{array}$ & $\begin{array}{l}\text { - } \\
\text { - } \quad \text { Localização } \\
\text { Parte } \\
\text { - Condição de } \\
\text { Acesso } \\
\text { Informação de } \\
\text { Registro }\end{array}$ & $\begin{array}{l}\text { Padrão de metadados } \\
\text { descritivos derivado do } \\
\text { esquema bibliográfico } \\
\text { MARC } 21 \text {, cujo o enfoque } \\
\text { são os recursos } \\
\text { eletrônicos e os serviços } \\
\text { de biblioteca (NATIONAL } \\
\text { INFORMATION } \\
\text { STANDARDS } \\
\text { ORGANIZATION, 2004). }\end{array}$ \\
\hline EAD & $\begin{array}{l}\text { - Esquema XML e uma } \\
\text { DTD para codificar } \\
\text { instrumentos de } \\
\text { pesquisa arquivísticos. } \\
\text { - Mantido pela LC junto } \\
\text { com a SAA. } \\
\text { - Compatível com as } \\
\text { normas de descrição } \\
\text { arquivística, tal como a } \\
\text { ISAD(G). }\end{array}$ & $\begin{array}{l}\text { - } \quad \text { Cabeçalho EAD } \\
\text { - } \quad \text { Descrição Arquiví }\end{array}$ & & $\begin{array}{l}\text { Padrão para codificação } \\
\text { de instrumentos } \\
\text { arquivísticos de acesso, } \\
\text { tais como inventários, } \\
\text { índices, dentre outros } \\
\text { (ANDRADE, 2007; } \\
\text { BARBEDO et al. 2007; } \\
\text { BARBEDO; CORUJO; } \\
\text { SANT'ANA, 2011; CHAN; } \\
\text { ZENG, 2006). }\end{array}$ \\
\hline
\end{tabular}


Quadro 1 - Padrões e elementos de metadados de apoio à preservação digital (Final).

\begin{tabular}{|c|c|c|c|}
\hline Padrão & Características & $\begin{array}{l}\text { Elementos de metadados } \\
\text { úteis para a preservação } \\
\text { digital }\end{array}$ & Escopo \\
\hline $\begin{array}{c}\text { ANSI/NISO } \\
\text { Z39.87 }\end{array}$ & $\begin{array}{l}\text { - Inclui metadados técnicos } \\
\text { para gestão de coleções de } \\
\text { imagens fixas digitais. } \\
\text { - Implementado e adotado } \\
\text { via esquema XML NISO } \\
\text { MIX mantido pela LC. } \\
\text { - Compreende metadados } \\
\text { para preservação e } \\
\text { metadados administrativos. }\end{array}$ & $\begin{array}{l}\text { - Informação Básica do } \\
\text { Objeto Digital } \\
\text { Informação Básica da } \\
\text { Imagem } \\
\text { - Metadados de Captura da } \\
\text { Imagem } \\
\text { Metadados de Avaliação da } \\
\text { Imagem } \\
\text { Histórico de Mudança }\end{array}$ & $\begin{array}{l}\text { Padrão de metadados técnicos } \\
\text { para desenvolver, intercambiar } \\
\text { e interpretar arquivos de } \\
\text { imagem fixa digital, facilitar a } \\
\text { interoperabilidade entre } \\
\text { sistemas, serviços e software, } \\
\text { assim como apoiar a gestão a } \\
\text { longo prazo e o contínuo } \\
\text { acesso a coleções de imagens } \\
\text { digitais (BARBEDO et al. 2007; } \\
\text { NATIONAL INFORMATION } \\
\text { STANDARDS } \\
\text { ORGANIZATION, 2004, } \\
\text { c2011). }\end{array}$ \\
\hline METS & $\begin{array}{l}\text { - Esquema XML mantido } \\
\text { pela LC para gestão de } \\
\text { objetos de biblioteca digital. } \\
\text { - Pode implantar e } \\
\text { padronizar os pacotes PSI, } \\
\text { PAI ou PDI no modelo SAAI. } \\
\text { - Organiza e expressa } \\
\text { relações hierárquicas e } \\
\text { hiperligações entre os } \\
\text { objetos e suas partes. } \\
\text { - Inclui DC, MODS, EAD e } \\
\text { MIX na seção de Metadados } \\
\text { Descritivos, e pode ter o } \\
\text { PREMIS na seção de } \\
\text { Metadados Administrativos. }\end{array}$ & $\begin{array}{ll}\text { - } & \text { Cabeçalho METS } \\
\text { - } & \text { Metadados Descritivos } \\
\text { - } & \text { Mapa Estrutural } \\
\text { - } & \text { Ligações Estruturais } \\
\text { - Comportamento }\end{array}$ & $\begin{array}{l}\text { Padrão para codificar } \\
\text { metadados descritivos, } \\
\text { administrativos e estruturais } \\
\text { sobre objetos digitais num } \\
\text { repositório (ALMEIDA; } \\
\text { CENDÓN; SOUZA, 2012; } \\
\text { BARBEDO et al. 2007; } \\
\text { CAMPOS; SARAMAGO, 2007). }\end{array}$ \\
\hline PREMIS & $\begin{array}{l}\text { - Esquema XML de } \\
\text { metadados para suporte a } \\
\text { preservação digital em } \\
\text { repositórios. } \\
\text { - É mantido pela LC, } \\
\text { focaliza o sistema e sua } \\
\text { gerência e define unidades } \\
\text { semânticas. } \\
\text { - Pode ter apoio do DC, } \\
\text { MODS, EAD e MIX na } \\
\text { verificação da autenticidade, } \\
\text { integridade, procedência ou } \\
\text { direitos relativos aos objetos } \\
\text { mantidos num repositório } \\
\text { digital. }\end{array}$ & $\begin{array}{l}\text { Entidade Intelectual } \\
\text { - Objeto } \\
\text { - Eventos } \\
\text { - Agentes } \\
\text { - Direitos }\end{array}$ & $\begin{array}{l}\text { Padrão que define um conjunto } \\
\text { de elementos básicos para } \\
\text { codificar, armazenar, gerir e } \\
\text { intercambiar metadados de } \\
\text { preservação no contexto de um } \\
\text { sistema de repositório para } \\
\text { preservação digital } \\
\text { (ARELLANO, 2008; CAMPOS; } \\
\text { SARAMAGO, 2007; SAYÃO, } \\
\text { 2010). }\end{array}$ \\
\hline
\end{tabular}


A princípio, é notável frisar que todos estes padrões apontados podem ser representados na linguagem computacional XML. Visto que é um padrão aberto, não proprietário e entendível por aplicações variadas, a linguagem XML apoia as demandas de preservação de longo prazo e propicia o intercâmbio de dados entre sistemas, além de favorecer o uso combinado de diferentes esquemas, como o METS e o PREMIS com as informações descritivas do DC, MODS, EAD ou MIX. Ademais, temos a DCMI, no caso do DC, e o Network Development and MARC Standards Office da LC, para os outros padrões, onde padronizam a descrição e a representação das informações através de vocabulários controlados ou esquemas de codificação internacionalmente reconhecidos.

Utilizar conjuntamente distintos padrões de metadados torna-se plausível em razão dos tipos de recursos para serem descritos e dos vários processos de preservação digital. Não apenas os metadados para preservação são importantes, mas também os metadados descritivos, estruturais, administrativos e técnicos auxiliam o alcance da preservação por longo prazo. Desta maneira, não há como afirmar qual é o único esquema de metadados existente que assegure totalmente a preservação digital e, sim, que diferentes padrões podem trabalhar juntos, de modo a se auto complementarem para o registro eficaz das informações requeridas, na gestão da preservação e do acesso utilizável ao longo do tempo de objetos/recursos digitais.

Dentre os elementos de metadados que são relevantes e recorrentes em todos os padrões indicados estão os identificadores. Uma vez que os objetos digitais são frágeis, dinâmicos e volúveis, os identificadores provêm o acesso contínuo e confiável para os objetos como a localização ou a referência única e indubitável para estes em todo o seu ciclo de vida. O registro de informações de identificadores locais ou persistentes manifestam os metadados para preservação delineados na Informação de Descrição de Preservação (em especial, referência) do modelo SAAI, além do requisito de localizar e rastrear o objeto ao longo do tempo.

Os padrões DC, MODS e EAD são mais aplicáveis à descrição de recursos para fins de sua descoberta, busca, recuperação ou localização. Embora a eficácia dos esquemas apontados esteja intrinsicamente atrelada à etapa de acesso do que propriamente para a preservação, alguns dos seus elementos são relevantes para auxiliar os metadados de preservação PREMIS. Assim, as informações descritivas destes padrões apoiam tanto os requisitos de manter a autenticidade, a proveniência e o contexto do objeto digital como os metadados de preservação na Informação de Descrição de Preservação (principalmente, contexto e proveniência) do modelo SAAI.

Sob o enfoque da preservação por longo prazo, determinados elementos de metadados dos esquemas DC Qualificado, MODS e EAD requerem uma maior atenção, tais como:

- Descrição, Data, Formato, Identificador, Fonte, Relação, Cobertura, Direitos, Detentor de Direitos e Proveniência, no esquema DC Qualificado.

- Informação de Origem, Descrição Física, Índice, Item Relacionado, Identificador, Parte, Localização, Condição de Acesso e Informação de Registro, no esquema MODS.

" Cabeçalho EAD e Descrição Arquivística, no esquema EAD.

Embora esteja fora do seu escopo, os metadados técnicos ANSI/NISO Z39.87 ou MIX podem ser usados com o PREMIS na comprovação da procedência, autenticidade e integridade de imagens digitais. Além de metadados sobre os aspectos técnicos de imagens, o ANSI/NISO Z39.87 possui também metadados de preservação e administrativos. Isto posto, todas as seções de metadados Z39.87 devem ser levadas em consideração, visto que amparam os metadados de preservação na Informação de Descrição de Preservação (contexto, proveniência e fixidade) e os requisitos de salvaguardar a autenticidade, a proveniência e o contexto do objeto digital.

Por sua vez, o METS pode atuar na padronização dos pacotes de informação PSI, PAI ou PDI no modelo SAAI, armazenando metadados - descritivos, estruturais, administrativos e de preservação - associados a um objeto digital num sistema. É útil para simplificar a ordem e a gerência das partes constituintes de objetos complexos (Seção de Arquivos) e seus metadados, ou expressar as relações hierárquicas e hiperligações (Mapa Estrutural e Ligações Estruturais) entre os vários arquivos que compõem os objetos ou entre diferentes objetos digitais. Algumas seções num documento METS são notáveis para a preservação, dando suporte aos requisitos de manter o contexto e as funcionalidades do objeto digital e para os metadados de preservação na Informação de Descrição de Preservação (especialmente, contexto), tais como: Cabeçalho METS, Mapa Estrutural, Ligações Estruturais e Comportamento. 
Em razão do PREMIS refletir diretamente o modelo de informação SAAl e os requisitos de preservação digital, todas as suas entidades ou seções de metadados são significantes. Tendo em vista as discussões realizadas neste trabalho consideramos que, num sistema de repositório baseado no SAAI, o METS pode ser utilizado como um esquema central para a administração dos objetos digitais, englobando os padrões DC, MODS, EAD e MIX na seção de Metadados Descritivos, além do padrão PREMIS na seção de Metadados Administrativos. Todavia, temos que ponderar também a ocorrência de problemas de duplicação, sobreposição e equivalência entre os conjuntos de metadados no uso concomitante destes diferentes esquemas.

\section{Considerações finais}

Os desafios da preservação digital estão associados à natureza dos objetos digitais e seu ambiente, à obsolescência tecnológica e aos direitos de propriedade intelectual. É desejável não apenas salvaguardar o acesso contínuo aos conteúdos, mas também assegurar que os objetos sejam localizados ao longo do tempo somado à preservação do leiaute, das funcionalidades, da origem e do contexto, o qual suportam a comprovação de sua autenticidade e integridade. Estes aspectos refletem basicamente os requisitos para consecução da preservação de longo prazo.

Existem diferentes estratégias para o processo de preservação digital. Em razão de sua ampla aplicação em instituições e da não exigência de grandes recursos, a migração demostra ser útil para a maioria das políticas institucionais de preservação digital. A adoção de metadados para preservação apoia a administração dos processos relativos ao arquivamento e à manutenção do acesso à informação digital a longo prazo, com garantias de autenticidade, de integridade e de confiabilidade.

Os padrões de metadados podem propiciar a interoperabilidade dos objetos digitais, oferecer ou orientar o uso de vocabulários controlados e esquemas de codificação, bem como possibilitar a descrição conjunta ou a incorporação de metadados provindos de outros esquemas XML.

$\mathrm{Na}$ pesquisa foram identificados, sistematizados e analisados os padrões de metadados para a preservação digital, articulados à Ciência da Informação e a áreas afins. Os metadados descritivos e técnicos do DC, MODS, EAD e ANSI/NISO Z39.87 ou MIX, possuem um papel mais direcionado a amparar o METS e o PREMIS, tanto na descoberta e no registro dos aspectos técnicos do objeto digital, como na comprovação de sua procedência, autenticidade, contexto e integridade. Englobando metadados descritivos, estruturais, administrativos e de preservação do PREMIS, o METS pode gerir os objetos digitais atuando como um Pacote de Submissão de Informação (PSI), Pacote de Arquivamento de Informação (PAI) ou Pacote de Disseminação de Informação (PDI) num SAAI.

Determinados elementos de metadados dos padrões identificados puderam ser sinalizados nesta investigação como sendo úteis para a preservação digital em repositórios. Nos padrões DC e MODS, por exemplo, os elementos indicados no Quadro 1 incluem algumas das informações previstas nos metadados de preservação PREMIS, como os direitos de propriedade intelectual e seus detentores, a identificação única para o objeto digital, os outros objetos relacionados ao objeto que está sendo descrito e as dependências técnicas do objeto.

Os resultados neste trabalho dispõem um respaldo teórico, técnico e sistematizado de esquemas que podem ser utilizados em repositórios institucionais, construídos para atender a preservação e o acesso a longo prazo de informações digitais. Os elementos de metadados julgados na pesquisa como úteis na preservação digital contribuirão para a escolha dos padrões segundo as demandas da instituição, ou para o reconhecimento do conjunto de informações necessárias para garantir a preservação e a administração de conteúdos digitais em C\&T num sistema.

Destaca-se que a garantia de preservação digital a longo prazo só será possível com a adoção efetiva de padrões ou esquemas de metadados, pois são eles que determinarão a descrição, a representação, a consistência e a persistência do recurso/objeto digital no ambiente informacional, além de definir a interoperabilidade entre sistemas. 


\section{Referências}

ALMEIDA, M. B.; CENDÓN, B. V.; SOUZA, R. R. Metodologia para implantação de programas de preservação de documentos digitais a longo prazo. Encontros Bibli: Revista Eletrônica de Biblioteconomia e Ciência da Informação, v. 17, n. 34, p. 103-130, maio./ago., 2012. Disponível em: <https://periodicos.ufsc.br/index.php/eb/article/view/15182924.2012v17n34p103/22622>. Acesso em: 9 jul. 2016.

ANDRADE, R. S. Aspectos introdutórios da representação de informação arquivística: a Norma Brasileira de Descrição Arquivística (Nobrade), a Descrição Arquivística Codificada (EAD-DTD) e o projeto Archives Hub. Ponto de Acesso, Salvador v. 1, n. 2, p. 70-100, jul./dez. 2007. Disponível em: <http://www.portalseer.ufba.br/index.php/revistaici/article/view/1589/1813>. Acesso em: 9 jul. 2016.

ARELLANO, M. Á. M. Critérios para a preservação digital da informação científica. 2008. 354 f. Tese (Doutorado em Ciência da Informação) - Departamento de Ciência da Informação e Documentação, Universidade de Brasília, Brasília, 2008. Disponível em: <http://repositorio.unb.br/bitstream/10482/1518/1/2008 MiguelAngelMarderoArellano.pdf>. Acesso em: 9 jul. 2016.

BARBEDO, F. et al. RODA: repositório de objectos digitais autênticos. Actas dos Congressos Nacionais de Bibliotecários, Arquivistas e Documentalistas, Lisboa, n. 9, 2007. Disponível em: <http://www.bad.pt/publicacoes/index.php/congressosbad/article/view/535/320>. Acesso em: 9 jul. 2016.

BARBEDO, F.; CORUJO, L.; SANT'ANA, M. Recomendações para a produção de planos de preservação digital. Lisboa: Direção-Geral do Livro, dos Arquivos e das Bibliotecas (DGLAB), nov. 2011. 111 p. Disponível em: <http://arquivos.dglab.gov.pt/wp-content/uploads/sites/16/2014/02/Recomend producao PPD V2.1.pdf>. Acesso em: 9 jul. 2016 .

CAMPOS, F. M. G.; SARAMAGO, M. L. Preservação digital de longo prazo em instituições patrimoniais: reutilização e adaptação de metadados. Actas dos Congressos Nacionais de Bibliotecários, Arquivistas e Documentalistas, Lisboa, $\mathrm{n}$ 9, p. 1-7, 2007. Disponível em: <http://www.bad.pt/publicacoes/index.php/congressosbad/article/view/540/330>. Acesso em: 9 jul. 2016.

CAPLAN, P. Understanding PREMIS. [Washington, DC]: Library of Congress Network Development and MARC Standards Office, feb. 2009. 26 p. Disponível em: <http:/www.loc.gov/standards/premis/understanding-premis.pdf>. Acesso em: 9 jul. 2015.

CHAN, L. M.; ZENG, M. L. Metadata interoperability and standardization: a study of methodology part i: achieving interoperability at the schema level. D-Lib Magazine, v. 12, n. 6, june 2006. Disponível em: <http://www.dlib.org/dlib/june06/chan/06chan.html>. Acesso em: 9 jul. 2016.

CHEN, M.; REILLY, M. Implementing METS, MIX, and DC for Sustaining Digital Preservation at the University of Houston Libraries. Journal of Library Metadata, v. 11, n. 2, p. 83-99, may 2011. Disponível em: <http://www.tandfonline.com/doi/full/10.1080/19386389.2011.570662\#abstract>. Acesso em: 9 jul. 2016.

DUBLIN CORE METADATA INITIATIVE (DCMI). History of the Dublin Core Metadata Initiative. c2015. Disponível em: <http://dublincore.org/about/history/>. Acesso em: 9 jul. 2016.

FERREIRA, Carla Alexandra Silva. Preservação da Informação Digital: uma perspectiva orientada para as bibliotecas. Coimbra: [s.n.]. 2011.

FORMENTON, D. Identificação de padrões de metadados para preservação digital. 2015. 102 f. Dissertação (Mestrado em Ciência, Tecnologia e Sociedade) - Centro de Educação e Ciências Humanas, Universidade Federal de São Carlos, São Carlos, 2015

FORMENTON, D.; GRACIOSO, L. S.; CASTRO, F. F. Revisitando a preservação digital na perspectiva da ciência da informação: aproximações conceituais. Revista Digital de Biblioteconomia e Ciência da Informação, Campinas, SP, v. 13, n. 1, p. 170-191, jan./abr. 2015. Disponível em: <http://periodicos.sbu.unicamp.br/ojs/index.php/rdbci/article/view/1587/1571 >. Acesso em: 9 jul. 2016.

GAMA, F. A.; FERNEDA, E. A Mediação da Informação nos Arquivos Permanentes: serviços de referência arquivística no ambiente digital. Informação \& Informação, Londrina, v. 15, n. 2, p. 148-169, jul./dez. 2010. Disponível em: $<$ http://www.uel.br/revistas/uel/index.php/informacao/article/view/7352/7005>. Acesso em: 9 jul. 2016.

GRÁCIO, J. C. A. Preservação digital na gestão da informação: um modelo processual para as instituições de ensino superior. São Paulo, SP: Cultura Acadêmica, 2012. 214 p. Disponível em: <http://www.culturaacademica.com.br/ img/arquivos/Preservacao digital na gestao da informacao-WEB v2.pdf>. Acesso em: 9 jul. 2016.

HARPER, C. A. Dublin Core Metadata Initiative: beyond the element set. Information Standards Quarterly (ISQ), v. 22, n. 1, p. 19-28, winter 2010. Disponível em: <http://www.niso.org/apps/group public/download.php/3670/FE DCMI Harper isqv22no1.pdf>. Acesso em: 9 jul. 2016.

HILLMANN, D. Using Dublin Core. Nov. 2005. Disponível em: <http://dublincore.org/documents/usageguide/>. Acesso em: 9 jul. 2016. 
LAVOIE, B.; GARTNER, R. Preservation metadata. 2nd edition. DPC Technology Watch Report, v. 13, n. 3, p. 1-36, may 2013. Disponível em: <http://dx.doi.org/10.7207/twr13-03>. Acesso em: 9 jul. 2016.

LIBRARY OF CONGRESS. METS: an overview \& tutorial. Sept. 2011. Disponível em: <http://www.loc.gov/standards/mets/METSOverview.v2.html>. Acesso em: 9 jul. 2016.

LIBRARY OF CONGRESS. MODS User Guidelines. MODS elements and attributes. Version 3. Nov. 2014. Disponível em: <http://www.loc.gov/standards/mods/userguide/>. Acesso em: 9 jul. 2016.

NATIONAL INFORMATION STANDARDS ORGANIZATION (NISO). Data Dictionary: technical metadata for digital still images. Baltimore: NISO, c2011. 104 p. Disponível em: <http://www.niso.org/apps/group public/download.php/14698/z39 872006 r2011.pdf>. Acesso em: 9 jul. 2016.

NATIONAL INFORMATION STANDARDS ORGANIZATION (NISO). Understanding metadata. Bethesda: NISO Press, 2004. 16 p. Disponível em: <http://www.niso.org/publications/press/UnderstandingMetadata.pdf>. Acesso em: 9 jul. 2016.

NATIONAL MUSEUM OF AUSTRALIA. Digital preservation and digitisation policy. Version 2.2. Canberra, aug. $2012.11 \mathrm{p}$. Disponível em: <http://www.nma.gov.au/ data/assets/pdf file/0013/1453/POL-C-028 Digital preservation and digitisation2.2 public.pdf>. Acesso em: 9 jul. 2016.

RODRIGUES, N. A. Introdução ao METS: preservação e intercâmbio de objetos digitais. Encontros Bibli: Revista Eletrônica de Biblioteconomia e Ciência da Informação, Florianópolis, v. 13, n. 26, p. 1-16, 2008. Disponível em: $<$ https://periodicos.ufsc.br/index.php/eb/article/view/1518-2924.2008v13n26p172/6644>. Acesso em: 9 jul. 2016

SARAMAGO, M. L. Metadados para preservação digital e aplicação do modelo OAIS. Actas dos Congressos Nacionais de Bibliotecários, Arquivistas e Documentalistas, Lisboa, n. 8, p. 1-6, 2004. Disponível em: <http://www.bad.pt/publicacoes/index.php/congressosbad/article/view/640/637>. Acesso em: 9 jul. 2016.

SAYÃO, L. F. Uma outra face dos metadados: informações para a gestão da preservação digital. Encontros Bibli: Revista Eletrônica de Biblioteconomia e Ciência da Informação, Florianópolis, v. 15, n. 30, p. 1-31, 2010. Disponível em: $<$ https://periodicos.ufsc.br/index.php/eb/article/view/1518-2924.2010v15n30p1/19527>. Acesso em: 9 jul. 2016.

SOCIETY OF AMERICAN ARCHIVISTS. Encoded Archival Description Working Group. Encoded Archival Description Tag Library: version 2002. Chicago, 2002. 308 p. (EAD Technical Document, n. 2). Disponível em: <http://www2.archivists.org/sites/all/files/EAD TagLibrary 2002.pdf>. Acesso em: 9 jul. 2016.

ZENG, M. L.; QIN, J. Metadata. New York: Neal-Schuman Publishers, 2008. 365 p. 


\section{Dados dos autores}

\section{Danilo Formenton}

Mestre em Ciência, Tecnologia e Sociedade pela Universidade de São Carlos - UFSCar. Graduado em Biblioteconomia e Ciência da Informação pela UFSCar.

formenton.danilo@gmail.com

\section{Fabiano Ferreira de Castro}

Professor Adjunto do Programa de Pós-graduação em Ciência da Informação e do Departamento de Ciência da Informação da UFSCar.

fabianocastro.ufscar@gmail.com

\section{Luciana de Souza Gracioso}

Docente do Programa de Pós-graduação em Ciência da Informação e do Departamento de Ciência da Informação da UFSCar.

lugracioso@yahoo.com.br

\section{Ariadne Chloe Mary Furnival}

Docente do Programa de Pós-graduação em Ciência da Informação e do Departamento de Ciência da Informação da UFSCar.

chloe@ufscar.br

Maria da Graça de Melo Simões

Professora auxiliar da Faculdade de Letras da Universidade de Coimbra, no Departamento de Filosofia, Comunicação e Informação.

gsimoes@fl.uc.pt

Recebido - Received: 2017-01-24

Aceitado - Accepted: 2017-12-24

\section{(oc) EY}

This work is licensed under a Creative Commons Attribution 4.0

United States License.

\section{UILIS D-Sulte?}

This journal is published by the University Library System of the University of Pittsburgh as part of its

D-Scribe Digital Publishing Program and is cosponsored by the University of Pittsburgh Press. 